\title{
Farmers' market or farmers market? Examining how market ownership influences conduct and performance
}

\author{
Snehalatha Gantla ${ }^{\text {** }}$ and Larry Lev ${ }^{\mathrm{b}}$ \\ Oregon State University
}

Submitted February 5, 2015 / Revised May 16, 2015 / Accepted June 1, 2015 /

Published online November 15, 2015

Citation: Gantla, S., \& Lev, L. (2015). Farmers' market or farmers market? Examining how market

ownership influences conduct and performance. Journal of Agriculture, Food Systems, and Community

Development, 6(1), 49-63. http://dx.doi.org/10.5304/jafscd.2015.061.005

Copyright (C) 2015 by New Leaf Associates, Inc.

\begin{abstract}
Over the last two decades, farmers markets have been widely recognized for their contributions to local economies, support of small-scale farmers, and ability to reconnect consumers and producers of food. Farmers markets vary substantially in both the goals they set and the outcomes they achieve. By conducting a comparative analysis, this study examines whether and how market ownership influences outcomes. Additionally, our study focuses not on determining which ownership type is "best," but on highlighting how markets differ, and more importantly, the limitations that need to be overcome for each type. The research uses Henry Hansmann's (1996) ownership of enterprise

a * Corresponding author: Snehalatha Gantla, School of Public

Policy, Oregon State University.

Gantla is now at Social Science Research Unit, Department of Agricultural Economics and Rural Sociology, University of Idaho; 875 Perimeter Dr. MS-2334; Moscow, ID 83843 USA; +1-208-885-5849; slgantla@gmail.com

b Larry Lev, Department of Applied Economics, Oregon State University; 213 Ballard Extension Hall; 2591 SW Campus Way; Corvallis, Oregon 97331 USA; +1-541-737-1417; larry.lev@oregonstate.edu
\end{abstract}

framework and Muhammad Yunus's (2010) social business framework to analyze whether differences in ownership lead to variations in market governance, conduct, and performance. Interviews were conducted with managers of Oregon farmers markets representing various ownership structures. Data were analyzed using the inductive thematic analysis approach to understand how ownership influences market goals and mission, general operations, and performance outcomes. The three major market ownership types, vendor-led, community-led, and subentities, have distinct benefits and challenges associated with them. Our findings indicate that vendor-led markets have strong ties back to their vendors but have weaker links to the communities that host the market and are less able to enhance the market by adding activities and pursuing additional fundraising. We found that community-led markets benefit from strong community ties and are often able to draw upon the energy and expertise of board members and volunteers. Their links back to producers depend on vendor representation on the governing body. Finally, markets that function as subentities of broader organizations have the potential for 
access to greater financial and managerial resources but are often relatively poorly linked to their vendors. These results provide useful insights both for those who are considering starting a market and for those who wish to improve the performance of existing markets.

\section{Keywords}

comparative analysis, farmers markets, governance, local food, market managers, performance, ownership, qualitative

\section{Introduction and Background}

\section{Introduction}

In recent times, consumer interest in local food has grown dramatically, as reflected in consumers' willingness to pay higher prices for locally grown food (Darby, Batte, Ernst \& Roe, 2008) and the growth of local food sales overall (Low \& Vogel, 2011). Local food sourcing through direct-marketing strategies such as farmers markets, community supported agriculture, farm stands, and others enables producers to sell directly to consumers and increase their profit margin by receiving higher prices than are offered by wholesale markets.

Farmers markets, in particular, play an important role in developing local food systems and supporting small farms (Stephenson, 2008). These markets also increase economic activity in a community, help address food access and security issues, and serve as a general community-building mechanism. In providing these diverse benefits, markets serve a range of interest groups, including farmers, consumers, local businesses, and community organizations. It is increasingly common to have some combination of these actors involved in organizing and operating farmers markets. That is, many newer farmers markets are not farmers' markets $^{1}$ because farmers neither own nor operate them. This study explores how market ownership influences the priorities, processes, and outcomes of the market. Through qualitative interviews, we

\footnotetext{
1 The distinction between "farmers' market" and "farmers market" is more than the absence of an apostrophe. A "farmers' market" implies that farmers or, in general, vendors, are the ones who own and operate the market. Contrastingly, "farmers
}

document how market conduct and performance differ based on market ownership. The final goal of this research is to inform best practices in organizing and operating farmers markets. Despite the overall growth in number of farmers markets, many of them fail (Stephenson, 2008). Findings and recommendations from this research may help to reduce failure rates for new markets and improve the performance of existing markets. Additionally, we highlight advantages and limitations of each market ownership type so that practitioners can better anticipate the weaknesses they will need to overcome for a particular structure.

\section{Background}

Farmers markets were in decline for much of the twentieth century and then surged in popularity in the 1990s. By 2014, the U.S. Department of Agriculture (USDA) listed over 8,200 farmers markets across the nation, a 3.6\% increase from 2012 (USDA, Agricultural Marketing Service [USDA AMS], 2014). The Oregon Farmers Markets Association, a statewide organization, listed 160 markets during 2013 (Oregon Farmers Markets Association, n.d.). While farmers markets are significant because they support local food systems and local farmers, they also provide a hub for community gatherings and increase economic activity for surrounding businesses. As an example, Sadler, Clark, and Gilliland (2013) estimated the economic impact of farmers markets in Flint, Michigan, and London, Ontario, by taking into account the average amount of money spent among study respondents and total attendance at the markets each week. Using a market multiplier for each market, the researchers estimated that the annual impact of the London farmers market is CDN\$7.0 million while it is US\$6.8 million for Flint farmers market. Hughes, Brown, Miller, and McConnell (2008) examined the net economic impact of farmers markets in West Virginia by subtracting out reduced grocery store sales as a result of spending

market" does not convey who owns the market but describes the nature of a market as featuring products sold directly to consumers by farmers. The word "farmers" is an adjective in this second formulation. 
at farmers markets. They found that farmers markets provided a net positive increase of US $\$ 1.075$ million in sales and the addition of 43 full-time jobs. Though markets traditionally were grower-led efforts to carve out a niche for themselves, the focus on local food, and markets' multiple benefits have led to a wide variety of stakeholders becoming involved in the starting and running of farmers markets.

Exploring how ownership influences outcomes for market conduct and performance fills a knowledge gap in market literature. To date, there has been limited research on the organizational elements of farmers markets. In a study of Indiana farmers markets, Hofmann, Dennis, and Marshall (2008) hinted at a difference in performance of markets related to their organizational structure. Specifically, the authors found that, holding all other factors constant, markets that cited "provid[ing] farmers an outlet for their products" as the primary reason for the market's existence had 135 fewer customers on average than markets that cited "bring [ing] economic activity to the area" as the primary reason. The authors postulated that this difference could be a result of the expertise of the entity in charge of the market. For example, a government entity in charge of a market may have more advertising and marketing experience than a collection of vendors attempting to run a market.

\section{The Role of Ownership}

Farmers markets have a multitude of positive impacts, ranging from increased income for growers to revitalizing downtown areas, all of which create a strong incentive for various organizations and entities to start farmers markets. Hoffman et al. (2008) suggest that the organizational structure influences the way alternative food networks are operated. In order to examine the impact of ownership in market operations, we draw on The Ownership of Enterprise by Henry Hansmann (1996) and augment it to better suit the topic of this study. This framework allowed us to examine the costs and benefits of various types of market ownership. Hansmann defines ownership as the formal right to control and appropriate a firm's profits. As such, ownership effectively determines who has the power to do what with the firm's assets. Further- more, ownership is the way that members of a firm gain access to the internal decision-making structure. This is achieved by allocating voting rights to some segment of the firm's patrons, investors, or other parties. In the case of a farmers market, this could be vendors, community members, city officials, or business associations. This variation in who controls a market led us to question whether markets with different ownership vary from a farmers' market, which implies vendor control.

In his analysis, Hansmann analyzes ownership structures using two criteria: the costs of contracting and the costs of ownership. Sources of the costs of contracting include market power, dependent relationships with various groups, risks of long-term contracting, asymmetric information, conflicts of interest, and alienation. In the context of farmers markets, contracting can be interpreted as whether vendors organize markets themselves or participate in markets that are organized by other parties. Costs of ownership stem from the costs of controlling managers, collective decision-making, risk-bearing, and costs of transition. In this characterization, the most efficient ownership structure is that which best minimizes costs. Though Hansmann argues that subjective interests and values can be incorporated into assessing the costs of an ownership structure, he does not consider that ownership structure itself could be a reflection of values that are considered independently from their costs. Furthermore, the goal of cost minimization when selecting a particular ownership structure may not hold true for farmers markets. One criticism of Hansmann's assessment of ownership is that he does not consider the benefits of different ownership structures. Additionally, his fundamental definition of ownership as "exercise of control and receipt of residual earnings" fails to consider ownership of assets and property, which becomes particularly relevant in the case of nonprofit enterprises that do not strictly have a class of owners (Orts, 1998).

Assignment of ownership determines who makes decisions, and therefore which interests have the most influence. Because the decisionmaking body of a firm determines the rules of operation, allocation of ownership rights influences the priorities and processes of the governing body. 
In the context of a farmers market, analyzing who is part of the governance structure, what the priorities and processes are, and the outcomes of the market will demonstrate the influence that ownership may have on market conduct and performance. However, it is worth noting that this relationship between ownership, conduct, and performance is not necessarily unidirectional. It could be that the economic performance of a farmers market, in addition to the principles by which it is governed, influences its decision to maintain or alter a particular ownership structure.

Hansmann's framework is useful in evaluating the costs and benefits of ownership types. However, it does not consider how institutional values may affect the impact of ownership on a firm's outcomes. We incorporated the social business framework developed by Muhammad Yunus (2010) to supplement Hansmann's work and examine the role of ownership in a mission-driven organization.

Farmers markets are different from typical enterprises in that they may choose to seek multiple social objectives. From supporting local farmers to building stronger local economies, markets often have social values at the center of their operations. Social businesses are characterized by a handful of specific principles that distinguish them from nongovernmental organizations, social enterprises, and private businesses. A social business, while still having owners and investors, is primarily defined by its operational goal of addressing a perceived social problem (Yunus, 2010). This characteristic distinguishes a social business from a typical firm, whose goal is maximizing profit or minimizing cost.

Furthermore, a social business tries to improve its targeted social problems through the mechanism of selling goods or services. This enables the firm to be self-sustaining and thus distinct from a typical nonprofit, which is more reliant on charitable donations, grants, etc. Farmers markets generally charge vendors a nominal fee to be part of the market, which is the primary way the market is able to cover operational costs. However, many markets also seek other funding sources. In this paper, analyses of markets' funding sources and budget allocations reveal if markets are self-reliant and reinvest profits into the market, thus behaving like a social business in the mechanisms they use to address specific social problems.

Finally, Yunus constructs social businesses as part of a larger, systemic solution that is a "clearly defined alternative in order to change mindsets, reshape economic structures, [and] encourage new forms of thinking" (2010, p. 16). At this stage, we know that farmers markets are a mechanism that allow small-scale farmers to realize profits in the face of stiff global competition. In addition, farmers markets attempt to redefine the food system by focusing on principles of local and sustainable production and expanding consumer access to healthy foods. In this sense, they fit this final principle that social businesses act as an alternative. These facets of farmers markets are analyzed through interview questions pertaining to market goals and priorities, the mission of the market, and the particular efforts that the market pursues.

\section{Applied Research Methods}

The goal of this research is to understand how markets with different ownership forms differ in how they operate and what their outcomes are. Since these themes rely on understanding priorities, processes, and activities of market organizations, an interview method was suitable because it allowed for detailed descriptive data (Creswell, 2003).

\section{Data Collection}

\section{Participant population and sampling}

We compiled a complete list of Oregon farmers markets by crosschecking lists available from the Oregon Explorer project (Oregon Explorer, n.d.), the U.S. Department of Agriculture (USDA AMS, n.d.), and the Oregon Farmers Markets Association (Oregon Farmers Markets Association [OFMA], n.d.). Next, we consulted a former OFMA president and examined market websites and social media pages to confirm that the markets were still operating and to classify them by ownership type. Privately run market organizations were not included in this study because there are very few in Oregon. Through this process we constructed a list of 136 market organizations. 
An initial recruitment letter was sent via email to organizations' listed contacts. Email bounces were recorded and added to the list of organizations to be contacted via telephone. A second participation request was made two weeks later via email. Organizations that did not have an email contact listed or whose email bounced were contacted via phone. In two cases, a board member was interviewed because the organization did not have a market manager in place.

\section{Questionnaire and interviews}

The interview questionnaire had four parts: general information (characteristics of respondent and market), governance structure (management and decision-making structure of market), market conduct (goals, decision-making, organizational capacity), and market performance (economic and social measures). Questions were developed to flesh out each of these aspects from the participating markets. All interviews were conducted via telephone by the primary researcher. A total of 29 phone interviews were conducted, yielding a response rate of roughly $21 \%$. We stopped conducting interviews when new data added little to patterns that had already emerged (Merriam, 2009). All interviews were digitally recorded and transcribed for analysis. Markets with fewer than 10 vendors are managed quite differently from larger ones (Stephenson, 2008), and on this basis three markets, each with six or fewer vendors, were excluded from the study. In addition, one market was dropped from analysis due to poor recording quality, so 25 interviews were used in the analysis.

\section{Data Analysis}

The unit of analysis for this study is a market organization. An individual market organization can be in charge of running multiple markets. For example, a single organization operates the Corvallis Saturday Farmers' Market, Corvallis Wednesday Farmers' Market, and Albany Saturday Farmers' Market. Since the legal structure and governance of these markets are shared, it makes sense for the unit of analysis to be a market organization rather than an individual market. The 25 interviews used for analysis in this study represent 49 individual markets.
All data were transcribed and analyzed by the primary researcher, who was a graduate student at the time and had graduate-level experience with analyzing qualitative data. Data analysis was conducted inductively, with most of the themes being developed from patterns in the data (Boyatzis, 1998). Transcribed data were analyzed for the three major themes of ownership, conduct, and performance. While these three overarching themes were predetermined, data were also coded according to additional subthemes that emerged during the interview and data analysis process. Using predetermined themes allowed our analysis to be focused on answering the main question of the study, "how does conduct and performance of markets differ based on their ownership?" The use of emergent coding allowed us to take advantage of the rich data. The combination of these two qualitative analysis methods provided the opportunity to focus the analysis while taking full advantage of the depth and richness of the interviews.

Data analysis of the interviews involved two levels of coding. Data were coded for first-level, descriptive codes, and then coded again for second-level, pattern codes. First-level coding was done by organizing each interview according to the questions in the interview questionnaire to see how responses differed across all participants. As mentioned previously, ownership, conduct, and performance are the three main themes of analysis. Additional subthemes for each of these themes, particularly conduct and performance, were developed through pattern coding. As patterns emerged across the predetermined themes, they were coded and developed into more specific subthemes. Within the theme of conduct, we considered the following subthemes and variables (in parentheses): control of market (role of governing body and market manager), market orientation (mission, prioritization of goals), and access to and use of resources (sources of financial support). In order to assess market performance, we considered the subthemes of ability to meet consumer demand, level of community engagement (social programs and efforts, and community support), growth potential, and challenges to growth. In addition to the three primary themes, our analysis found seven major subthemes. 


\section{Results}

\section{Ownership}

Three distinct ownership categories were defined based on the organization's legal structure and the composition of its governing body. Markets can either be independently run, where the market organization is legally recognized as its own entity, or they can be a subentity, where the market operates under the legal auspices of another organization. Governing bodies can be composed primarily of vendors with some representation from community members (vendor-led), or primarily of community members with some vendor representation (community-led). In looking at ownership through these two variables, three major ownership categories emerged: vendor-led, independent (referred to as 'vendor-led markets'); community-led, independent (referred to as 'community-led markets'); and subentities. One market that participated in the study operated as a subentity but had a governing body composed entirely of vendors. This market appeared to be an anomaly and was included in the "subentities" category of ownership for subsequent analysis. As seen in Table 1, among the 25 market organizations that participated in the study, 15 are legally independent. Seven of those 15 markets are governed by vendor-dominated boards, while eight are governed by boards composed primarily of community members. Of the seven vendor-led markets, four have boards composed only of vendors. The average number of vendors for the markets participating in the study was 69 for vendor-led markets, 62 for community-led markets, and 29 for subentities. The average age in years was 20.5 for vendor-led markets, 14 for community-led markets, and 8.4 for subentities. Table 2 in Appendix A shows these and additional details about the sample.

Markets that function as a subentity of a larger

\section{Table 1. Ownership of Market Organizations}

\begin{tabular}{|l|c|c|}
\hline & Vendor-Led & Community-Led \\
\hline Independent & 7 & 8 \\
\hline Subentity & 1 & 9 \\
\hline
\end{tabular}

organization often do not have vendor representation on the governing body. This makes sense, as the community organization would be well established with its own governing structure before starting a farmers market and developing vendor relations. Two markets that function as subentities have one vendor position on the board. Markets that operate as a subentity often share a governing body with the organization. The only exceptions to this are two markets that were largely autonomous but shared the legal designation of a larger organization. These markets have full autonomy in governance and fiscal sustainability, but are able to benefit from the organization's legal status as a taxexempt nonprofit. This is the circumstance under which one of the markets operating as a subentity has a vendor-led governing body.

\section{Conduct}

This section examines how markets in different ownership categories vary in their day-to-day market management, mission, and prioritizing of market goals, as well as the resources they use and have available.

\section{Control Over the Market}

The role of each market's governing body and manager's autonomy were analyzed side by side to understand who effectively has control over market operations and direction. Governance of a market involves selecting new market vendors, determining market operation rules, setting rules for what kind of vendors qualify to participate in the market, etc. For vendor-led markets, the board plays a governance role and delegates responsibility for day-to-day operations to the market manager. Most market boards in this category are not involved in market-day activities because of time conflicts with their vending responsibilities. Managers have the latitude to propose ideas or changes to market operations, but they do not have decision-making authority. In this ownership category, the ultimate control of the market rests with the market board, and all decisions require final approval from the board.

In markets with community-led boards, board members maintain their governance roles but also contribute to market operations by assisting in day- 
to-day activities, helping with fund-raising, and garnering sponsorships. Six out of ten communityled markets have boards that actively volunteer at the market. Another difference from vendor-led markets is that managers in this ownership category also wield considerable decision-making authority. In particular, managers of these markets often have the authority to make decisions regarding vendor selection, market rules, etc., and consult the board as needed. The manager's relationship with the governing body is collaborative and supportive to the extent that the board is actively willing and able to support the manager.

Similar to vendor-led markets, subentities generally do not have boards that are involved in day-to-day market activities. Beyond that, they have limited involvement in the governance of the market, often getting involved only when issues affect the whole organization. As a consequence, managers of these markets have a greater degree of autonomy. In some cases, managers have one or two people whom they could consult on decisions or to troubleshoot difficult issues. In subentityowned markets, managers may be the only ones with considerable knowledge about the market.

Based on this analysis of manager autonomy and the role of the governing body, market control can be viewed as a continuum. In vendor-led markets the board has final decision-making authority over major decisions and assigns day-to-day tasks to the manager. Markets operated as a subentity are on the opposite end of the spectrum, as their managers make both major and day-to-day decisions with limited board involvement. Community-led markets fall in between these two extremes. Managers of these markets generally have some latitude and authority, but members of the governing body play supportive roles for both decision-making and day-to-day operations.

\section{Market Orientation}

Markets across the three ownership categories also display differences in their mission and prioritization of goals, with some being primarily vendororiented and others primarily communityoriented. In order to gauge whether a market is more vendor- or community-oriented, comments pertaining to market mission and prioritization of goals were analyzed.

All seven vendor-led markets stated that the primary organizational mission is to provide a venue for local farmers to sell their products. Six out of seven of these markets were also established prior to 2000, a finding that supports previous research by Stephenson (2008) that reported a statistically significant relationship between when a market was founded and its primary mission. This is not to say that vendor-led markets do not pursue any community-oriented goals or that their missions have not evolved, but their main priority was and is to advance the success of vendors.

In contrast, community-led markets have more diverse missions. While some list providing access to local food for their community as the primary mission, others have multiple missions that include supporting local farmers and the local economy, and creating a community gathering space. This mix and variability in the missions of communityled markets can be explained by the fact that a wider variety of interests are involved in setting the mission for these markets.

Markets that are subentities overwhelmingly place the focus of the market on serving a perceived need in their community. Examples of these missions include increasing economic activity in the local area, serving low-access communities, and generally improving the community's access to local food. Because community organizations choosing to start a farmers market already have a well-established organizational mission, the market reflects that larger mission. For example, a market operated by a downtown association has the primary mission of creating economic activity in the community. Similarly, markets operated by nonprofit organizations with social missions are focused on expanding access and serving lowincome communities.

In addition to asking respondents about the mission of the farmers market, we also asked them to rank four goals in order of their priority to the market: vendor income, market income, addressing consumer demands and expectations, and community-building. The general trends observed in the analysis of market missions are also present in how markets ranked these goals. A clear difference emerged between independently organized markets 
and subentities. Both vendor-led and communityled markets, on average, ranked "vendor income" as their top priority. In contrast, markets that are subentities overwhelmingly ranked "communitybuilding" as the most important goal. Overall, among vendor-led markets, $43 \%$ (three out of seven) respondents ranked vendor-income as the most important goal. For community-led markets, $50 \%$ (four out of eight) ranked vendor income as the top priority. Most notably, among subentities, $70 \%$ (seven of ten) prioritized community-building over all other goals. Of the 25 respondents, only three ranked "market income" as the most important goal for the market (two of them are community-led and the other is a subentity).

Although markets recognize the importance of all four goals, they do exhibit differences in their priorities. Based on the mission and priority of goals of markets, it is clear that vendor-led markets and community-led markets are more focused on supporting and ensuring the success of vendors when compared with subentity markets.

\section{Use of and Access to Resources}

One of the potential advantages of a market being operated by an established organization is that it would not have to rely solely on market fees for financial support. Though 10 of the surveyed market organizations operate as subentities, only four received financial support from the parent organization. The markets supported by a parent organization received significant contributions, including both a designated program budget and salary for the market manager. Further analysis of sources of financial support for markets showed that all markets, regardless of ownership, rely on various market fees such as vendor fees, membership dues, and application fees to help cover market operations (Figure 1). However, community-led markets more actively tap into additional revenue sources, such as sponsorships, grants, or fundraising efforts. While $50 \%$ of subentities take advantage of donations and sponsorships, very few actively fund-raise or apply for grants. This may be a result of the level of board involvement required. Given the considerable time that grant-writing and fund-

Figure 1. Sources of Financial Support (Percentage of Markets Using Each Revenue Source)

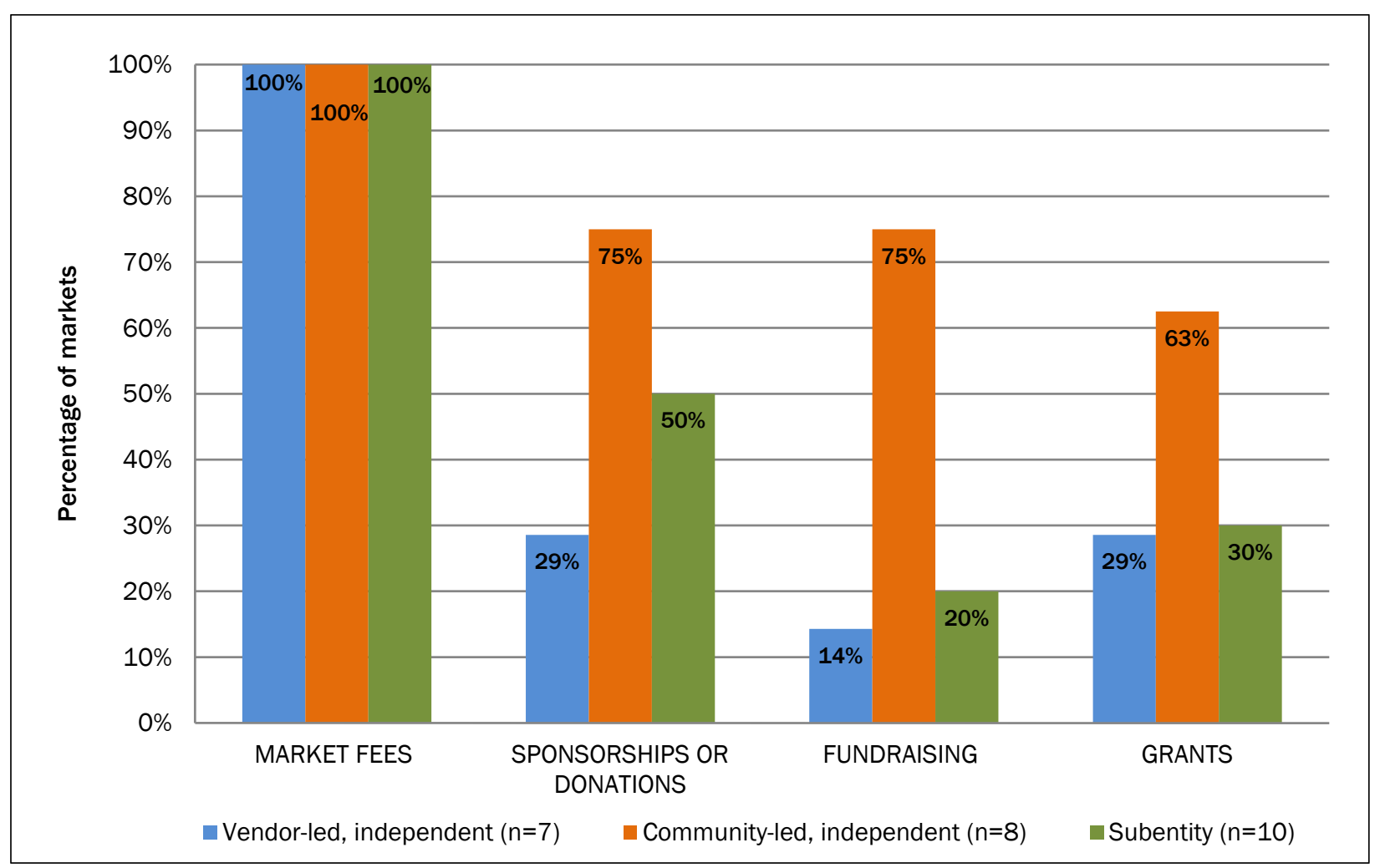


raising efforts take, a more involved board can support the manager both directly in accomplishing these tasks and indirectly by taking on other duties. In contrast, because vendor-led markets and subentities have governing bodies that are less involved in market operations, the manager's time is more likely to be taken up by these daily tasks.

Furthermore, while the sentiment is not present among all vendor-led markets, one vendorled market respondent voiced this reluctance to seek sponsorships:

We don't really like the imagery of us being partly run or controlled by an outside entity.... Since we can't even be a 501(c)(3) they're never going to grant us that because the farmers are making some money and they feel that that is not a charitable organization.

Despite this perception that a market organization has to have tax-exempt, 501(c)(3) status to take advantage of sponsorships, many community-led markets that operate on sponsorships do not have that legal status (which allows for tax-deductible donations). More importantly, the notion that outside financial contributions to the market hurt the image of the market is striking and may hint at a fundamental difference in values between vendor-led markets and other markets.

\section{Performance}

The performance outcomes of market organizations were analyzed based on market revenues, respondents' perceptions of current ability to meet demand, level of community engagement, growth potential, and types of barriers to growth.

\footnotetext{
${ }^{2}$ Murray's research explores how community involvement, in addition to consistent market presence, can improve market success. She finds that city support and strong connections with private organizations are crucial. Furthermore, garnering a mix of private and public support within the community and understanding vendor and customer needs to provide the best fit are important to embedding a farmers market.

${ }^{3}$ The Supplementary Nutritional Assistance Program (SNAP) is a federal program designed to provide food dollars for lowincome persons and families. SNAP funds are delivered to clients in the form of a credit card (in Oregon this is called the Oregon Trail Card) that can be used at participating vendors.
}

\section{Market Revenues}

Most markets operate on a very tight budget, barely managing to break even each year. Regardless of ownership type, markets typically use all of the market revenues to maintain or expand operations. Though uncommon, if a market has a budget surplus in a given year, it is allocated to the operational budget for the following year.

\section{Meeting Consumer Demand}

No specific pattern across ownership categories emerged when respondents were asked about the market's current ability to meet consumer demand. A market's ability to meet consumer demand seems to have more to do with the number of vendors at the market than its ownership structure. When ability to meet demand is considered in relation to the market's size, a clear pattern emerges where the largest markets appear to be doing extremely well while the smallest markets appear to be struggling. Three of the four markets with 15 or fewer vendors are located in central and eastern Oregon, where climate limits the growing season.

\section{Community Engagement}

Another subtheme examined to understanding market performance is community embeddedness (Murray, 2007). ${ }^{2}$ This is measured by whether markets have educational programs or outreach efforts, have SNAP match programs, ${ }^{3}$ and if they receive any in-kind donations or support from community organizations or members. Educational programs and outreach efforts range from programs that enable kids to shop at the market, gardening or cooking education, marketing efforts to reach particular communities (e.g., low-income,

It is increasingly common for all markets to accept SNAP dollars through the use of a token program, which allows customers to swipe their Oregon Trail Card at the market booth and receive tokens that can then be used at individual vendor booths. Vendors can later turn in these tokens to the market and receive monetary compensation. Several markets have what are called SNAP matching programs, where the value of SNAP customers' food dollars is subsidized. For example, if a market has a matching program for up to US $\$ 5$, SNAP customers can swipe their cards for US $\$ 5$, and receive an additional US $\$ 5$ in tokens, thus increasing their food dollars to US\$10. 
minority, elderly), to partnering with community organizations. Generally, community-led markets and subentities are more frequently engaged in these types of efforts.

While most of the markets in the sample were able to accept SNAP dollars, only 10 of the 25 markets subsidize low-income shoppers by providing a SNAP match program. Community-led and subentity markets more frequently provide SNAP match programs than vendor-led markets do. The relatively low percentage of markets that subsidize low-income customers may be explained by the considerable financial demands of such a program. As documented in Figure 2, community-led markets and subentity markets rely on external funding sources more frequently than vendor-led markets. This added financial stability allows the markets to pursue SNAP matching programs and improve low-income consumers' access to farmers markets. Lastly, nine out of 10 markets that operate as subentities received support from community organizations in the form of in-kind donations, such as use of private space with no charge, volunteer time, marketing or accounting services, etc. In addition to creating financial savings for the market, involvement by community groups also allows the market to expand its reach in terms of the programs and efforts it pursues:

We were able to get parking for vendors in an empty lot down by OHSU because they already knew us and we had relationships there. Having that parking available saves us close to [US] $\$ 6,000$ per year.

[For] the sprout corner, we work with an organization who has been quite involved with the market. And then also for music, we have this cooperative group who helps us find and book acts from the neighborhood.

Figure 2. Social Programs, Outreach Efforts, and Community Support (Percent Implementing Programs or Receiving Community Support)

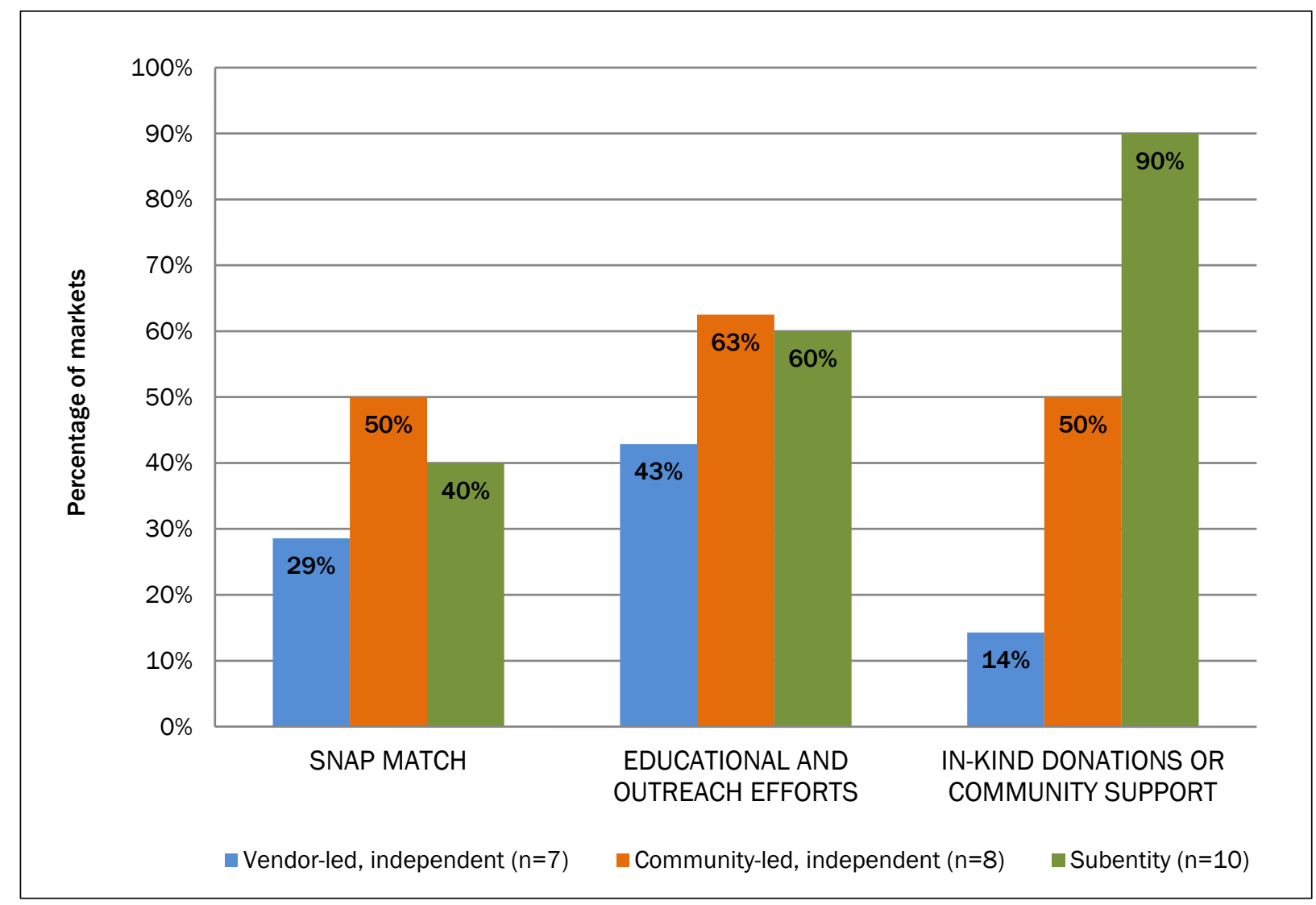




\section{Potential for Growth and Barriers}

Assessing growth potential and barriers to growth was complicated, as several factors not directly related to ownership demonstrated more influence. For example, climate, market size, geographical location of the market, and community size emerged as important factors in a market's outlook on growth and potential challenges. As a result, no significant patterns of growth and barriers in relation to ownership structure were apparent.

\section{Discussion}

\section{Ownership}

As evidenced in this study, the ownership or control of a farmers market has numerous implications. We used a combination of the legal structure of the market as well as the governing body's composition to divide markets into three primary categories: vendor-led, community-led, and subentity of another organization.

The primary advantage of vendor-led markets is that they are membership-oriented organizations rooted in their agricultural tradition and committed to advancing the interests of farmers. However, vendor-led markets face limitations because board members, who are vendors, have very little time to both assist with market-day operations and support additional market activities. Under this ownership type, a manager who is connected to the local community can be instrumental in developing community partnerships and building social capital for the market organization.

Community-led markets have diverse, multifaceted missions. They focus on both meeting community needs and increasing vendor incomes. The diverse makeup of these markets' boards develops the social capital and networks that can help the market access resources and increase its impact. A board composed of community members can devote more time to the market, enable the market organization to pursue additional activities, tap into more resources and connections, create more participation and buy-in from the community, and have a greater impact overall.

The last category, subentity markets, provide significant advantages, although with major limitations as well. The financial capacity of the parent organization as well as the nature of the relationship between the market and the organization are important factors in determining how much the market benefits. A market derives many more benefits when the market is truly a project of the organization, as opposed to an agreement of convenience that places the market under the umbrella of the parent organization's legal status. "Project" markets typically receive manager salaries and other resources from the parent organization. However, boards of subentity markets have limited involvement with the market, leaving the manager with little support. In the context of Hansmann's ownership framework, community-led markets and subentities allow vendors to trade ownership and control for fewer responsibilities in market operations. In order to avoid alienating vendors and ensure that vendor perspectives are still maintained, these types of market organizations can survey vendors and have vendor representation on the board.

\section{Conduct: Markets as a Social Business}

Although we predicted that the effect of varying ownership structures may be mitigated by the mission-driven nature of farmers markets, the results do not bear this out. One explanation is that although markets are mission-driven, differences in ownership and mission lead to variation in market conduct and performance. That said, most markets still meet some criteria laid out in Yunus's (2010) social business framework. Specifically, markets seem to be addressing social problems resulting from the market failure in providing community access to healthy food, providing a venue for small and local vendors, and boosting the resiliency of a local economy. Additionally, market revenues, when present, are reinvested into expanding and improving the services offered rather than simply benefiting the market vendors. However, in order to assess whether markets are effectively addressing social problems, further analysis of market vendors' revenues, low-income communities' access to healthy food, and evaluation of community food systems, all beyond the scope of this study, would be needed.

\section{Community Involvement and Market Orientation}

Pursuing sponsorships and donations from local 
businesses or community members provides one means of developing community buy-in and additional market resources. In doing so, the market's own efforts can be furthered as partnerships provide the resources necessary to implement SNAP match programs, facilitate educational activities for various groups, and attract additional volunteers. Invariably, this shifts the market from solely a membership-oriented organization toward a more community-oriented organization.

The shift in the focus of markets and structure of governing bodies indicate a larger trend wherein farmers markets are becoming a strategy to achieve goals beyond the redefining of food systems and supporting farmers. This is further supported by our data, which show that markets that were started after 2000 are more frequently community-led or subentities, and have missions that are broader in their focus. This shift in market orientation brings up the question of whether markets can continue to serve the interests of farmers and whether they ought to be considered farmers' markets. This is echoed by some respondents in the study who expressed a sentiment of staying true to "farmers' markets" as opposed to being a "farmers market." While the lack of the apostrophe on "farmers" may appear to be trivial, it indicates this greater shift in which markets are becoming a means to achieving different ends. This trend may in fact be better for individual communities. One respondent noted that a change in the market's orientation, inclusion of vendors or products that are not strictly agricultural, allowing resale of nonlocal products, etc., better addressed the needs of the community than a pure farmers' market. For example, a rural community seeking to bring fresh food to the community but facing the challenge of a tough growing climate and not enough farmers would stand to benefit from allowing the resale of products. Furthermore, addressing an existing need in the community may ensure the success of the market, rather than adding the challenge of creating demand. This finding supports Murray's (2007) recommendation that understanding customer and vendor needs and expectations can help tailor the market to better fit a community and ensure more embeddedness.
Performance: Implications for Vendors, Consumers, and Communities

This research project provides insight into how different market ownership types function and which aspects of each market type are most likely to need special attention. In general, vendor-led markets stay true to their agricultural traditions and focus on supporting local agriculture and producers. This means the market focus is oriented toward vendors, involvement from other organizations and community groups is often limited, and the market has fewer extra programs and activities. Additionally, a vendor-led structure is difficult to organize and maintain if vendors are traveling significant distances to participate in a market.

Community-led and subentity markets are in many respects better equipped to meet the demands of customers and communities. These markets target diverse goals in their missions. While they do not entirely ignore vendor success, having more community involvement and awareness of the needs of the community place these markets in a position to expand the impact of the market with more social programs like the SNAP match. The broader scope in the mission of the organization also encourages greater community buy-in. Most importantly, these markets are in a position to address particular community needs and work to fill those gaps.

\section{Recommendations}

A farmers market is started when a group senses a need and launches into action. As such, in most instances the ownership structure is defined by the initiating group, not selected from a set of alternatives. Therefore this research focused not on determining which structure is "best," but rather on showing how ownership types differ, and more importantly the weaknesses that need to be overcome for a particular ownership type. This information can help managers and board members be prepared to face specific challenges and adopt practices that can strengthen the market.

It is clear that farmers markets can serve as mechanisms for achieving a multitude of goals, from restructuring food systems to advocating on behalf of small-scale farmers, and improving the overall health and resiliency of a community. The 
broad reach of farmers markets means that a variety of stakeholders can be brought together in the organization. Partnership with a well-established community organization in the beginning can help to alleviate the start-up costs and stresses of creating a legal and organizational structure. Particularly, an established governing structure, recognition and standing in the community, access to financial sources, and important relationships eliminate extra steps that are necessary to start an independent market organization. This frees up valuable time and resources that can be better used to focus on recruiting vendors and building community support. This may ultimately help reduce market failure as markets operating as a project have more support in the initial stages when markets are most vulnerable (Stephenson, 2008). It is also possible that this relationship would not be permanent and the market could eventually develop a separate governing body.

We further recommend that market organizations recognize the benefits of bringing together diverse community members. As demonstrated by community-led markets, this enables the organization to tap into different skills, build partnerships, understand what gaps need to be filled in the community, and ensure community buy-in early on. Most importantly, this will create a more collaborative environment between the market organization and the community as well as increase the capacity of the organization, as it is less dependent on vendors who have limited time to give to market duties. Community members are able to contribute more time and effort to market operations as well as governance than vendors. Additionally, as markets draw vendors from different parts of the state or nearby states, encouraging vendor involvement may become more difficult. It also means that vendors are less rooted and aware of the community in which the market is operating. To encourage greater community participation and create more "local" ownership of the market, incorporating diverse members from the community is key.

While financial support through sponsorships, donations, and grants can increase market capacity and solidify relationships, these sources can also be inconsistent. Markets should work to ensure that their revenues are stable and able to support the organization's vital functions. Using additional resources like those listed above, however, can serve a vital role in expanding a market organization's reach and impact in the community through SNAP match programs, farm to school programs, etc.

\section{Conclusion}

This study tackles several important questions regarding how priorities and processes of market organizations differ across ownership, and the benefits and challenges associated with each. In general, farmers markets are becoming more diverse in the interests they serve and the roles they play in communities. While the overall trend is away from vendor-led markets, and new markets are more frequently developing under community-led and subentity structures, all three ownership types will continue to be observed. While this study focuses on markets in the state of Oregon, the investigation into the role of ownership in farmers markets fills a nationwide gap in knowledge on this topic. Consequently, the findings from this study can guide practitioners elsewhere in understanding what challenges and benefits they may encounter with specific types of organizational structures.

However, there is certainly need for additional research. The geographic focus on Oregon means that it may not fully capture the circumstances of market organizations in other areas of the United States. Privately owned markets were also excluded, so there is at least one more ownership structure that could be examined. Since respondents for this study were primarily market mangers, there may be some bias in their assessment or perception of market success and performance. Therefore, examining market rules, interviewing board members, vendors, customers, and surrounding business owners could provide more insight into market operations and performance, and community perceptions. Specifically, assessments of how well markets are satisfying their missions by looking at their overall impact in the community and the local food system, though difficult, may help us to further understand the significance of farmers markets in building local economies and local food systems.

We still need to understand more clearly how 
ownership structures differ in serving vendors, customers, and communities. Though the results from this study were able to offer some insight into this, there are many factors to be considered in further assessing vendor, customer, and community experience with farmers markets. Lastly, quantitative analysis examining the statistical relationship between ownership, conduct, and performance of market organizations can further advance the lessons learned from this study and provide more insight into the relationships that were identified.

\section{Acknowledgements}

We wish to express our sincere gratitude to Dr. Mark Edwards, Dr. Garry Stephenson, and Rebecca Landis for their assistance during the research process. We are also very grateful to the respondents who took time out of their schedules to participate in our study.

\section{References}

Boyatzis, R. E. (1998). Transforming qualitative information. Cleveland, Ohio: Sage.

Creswell, J. W. (2003). Research design: Qualitative, quantitative, and mixed methods approaches. Thousand Oaks, California: Sage.

Darby, K., Batte, M. T., Ernst, S., \& Roe, B. (2008). Decomposing local: A conjoint analysis of locally produced foods. American Journal of Agricultural Economics, 90(2), 476-486. http://dx.doi.org/ 10.1111/j.1467-8276.2007.01111.x

Hansmann, H. (1996). The ownership of enterprise. Cambridge, Massachusetts: Belknap Press.

Hofmann, C., Dennis, J. H., \& Marshall, M. I. (2008). An evaluation of market characteristics of Indiana farmers' markets. Paper prepared for presentation at the Southern Agricultural Economics Association Annual Meeting, Dallas, Texas. http://purl.umn.edu/6790

Hughes, D. W., Brown, C., Miller, S., \& McConnell T. (2008). Evaluating the economic impact of farmers' markets using an opportunity cost framework. Journal of Agricultural and Applied Economics, 40(1), 253-265.

Low, S. A., \& Vogel, S. (2011). Direct and intermediated marketing of local foods in the United States (Economic Research Report No. 128). Washington, D.C.:
USDA AMS. Retrieved from http://www.ers.usda. gov/publications/err-economic-researchreport/err128.aspx

Merriam, S. B. (2009). Qualitative research: A guide to design and implementation. San Francisco: Jossey-Bass.

Murray, M. K. (2007). Challenges to re-embedding food systems: Tracing the decline and revivial of a farmers' market on the edge (Unpublished master's dissertation). Oregon State University, Corvallis. Retrieved from http://hdl.handle.net/1957/5857

Oregon Explorer. (n.d.). Oregon explorer. Retrieved in 2013 from http://oregonexplorer.info/farm/ FarmersMarketsandRoadsideStandsFinder

Oregon Farmers Markets Association. (n.d.). Market Directory. Retrieved in 2013 from http://www.oregonfarmersmarkets.org/marketdirectory-2014/

Orts, E. W. (1998). Review: The future of enterprise organization. Michigan Law Review Association, 96(6), 1947-1974. http://dx.doi.org/10.2307/1290111

Sadler, R. C., Clark, M. A. R., \& Gilliland, J. A. (2013). An economic impact comparative analysis of farmers' markets in Michigan and Ontario. Journal of Agriculture, Food Systems, and Community Development, 3(3), 61-81. http://dx.doi.org/10.5304/jafscd.2013.033.009

Stephenson, G. (2008). Farmers' markets: Success, failure, and management ecology. Amherst, Massachusetts: Cambria Press.

U.S. Census Bureau. (2013, May 23). Community facts: Oregon. Retrieved in 2013 from http://factfinder.census.gov/faces/nav/jsf/pages/ community facts.xhtml

U.S. Department of Agriculture, Agricultural Marketing Service [USDA AMS]. (n.d.). Local food directories: National farmers market directory. Retrieved in 2013 from http://search.ams.usda.gov/farmersmarkets/

USDA AMS. (2014). Farmers markets and local food marketing. Retrieved from USDA: http://www.ams.usda.gov

Yunus, M. (2010). Building social business: The new kind of capitalism that serves humanity's most pressing needs. New York: PublicAffairs. Retrieved from http://www.ams.usda.gov/sites/default/files/ media/FarmersMarketDirectoryListing.jpg 


\section{Appendix A. Table 1. Characteristics of the Sample Markets}

\begin{tabular}{|c|c|c|c|c|}
\hline Geographical Location & $\begin{array}{c}\text { Year } \\
\text { Started }\end{array}$ & $\begin{array}{l}\text { Number of } \\
\text { Markets }\end{array}$ & $\begin{array}{c}\text { Size of } \\
\text { Largest Market a }\end{array}$ & Community Size $b$ \\
\hline Willamette Valley & 1998 & 3 & 160 & 157,429 \\
\hline Southern Oregon & 1994 & 2 & 60 & 21,884 \\
\hline Central Oregon & 1999 & 1 & 43 & 79,109 \\
\hline Willamette Valley & 2010 & 1 & 10 & Unincorporated \\
\hline Northern Coast & 1975 & 3 & 70 & 10,017 \\
\hline Southern Oregon & 1987 & 4 & 85 & 20,366 \\
\hline Willamette Valley & 1991 & 3 & 54 & 54,998 \\
\hline Portland Metro & 2002 & 1 & 46 & 603,106 \\
\hline Portland Metro & 1988 & 3 & 130 & 92,680 \\
\hline Portland Metro & 2005 & 3 & 50 & 32,755 \\
\hline Portland Metro & 1992 & 8 & 120 & 603,106 \\
\hline Portland Metro & 1998 & 1 & 80 & 95,327 \\
\hline Eastern Oregon & 2002 & 2 & 12 & 1,054 \\
\hline Willamette Valley & 2007 & 2 & 18 & 15,740 \\
\hline Northern Coast & 2006 & 1 & 40 & 605 \\
\hline Southern Coast & 2000 & 2 & 35 & 15,857 \\
\hline Portland Metro & 2007 & 1 & 25 & 603,106 \\
\hline Northern Coast & 2011 & 1 & 18 & 9,527 \\
\hline Portland Metro & 2012 & 1 & 35 & 603,106 \\
\hline Portland Metro & 2001 & 1 & 80 & 37,243 \\
\hline Willamette Valley & 2002 & 1 & 25 & 9,770 \\
\hline Central Oregon & 2009 & 1 & 15 & 2,118 \\
\hline Portland Metro & 2009 & 1 & 26 & 603,106 \\
\hline Eastern Oregon & 2011 & 1 & 11 & 7,110 \\
\hline Portland Metro & 1994 & 1 & 20 & 603,106 \\
\hline
\end{tabular}

a Size of market is based on the average number of vendors at the largest market run by the market organization.

b Population estimates are based on U.S. Census Bureau estimates for 2012 (U.S. Census Bureau, 2013). 